\title{
Initial Preserved Renal Function as a Predictor of Favorable Renal Response to Rituximab in Refractory or Relapsing Lupus Nephritis: A Single-center Cohort Study in Korea
}

\author{
Su Jin Choi, M.D. ${ }^{1,2}$, Soo Min Ahn, M.D. ${ }^{1}$, Ji Seon Oh, M.D., Ph.D. ${ }^{3}$, Seokchan Hong, M.D., Ph.D. ${ }^{1}$, \\ Chang-Keun Lee, M.D., Ph.D. ${ }^{1}$, Bin Yoo, M.D., Ph.D. ${ }^{1}$, Yong-Gil Kim, M.D., Ph.D. ${ }^{1}$ \\ ${ }^{1}$ Department of Rheumatology, Asan Medical Center, University of Ulsan College of Medicine, Seoul, ${ }^{2}$ Department of Rheumatology, Ulsan \\ University Hospital, University of Ulsan College of Medicine, Ulsan, ${ }^{3}$ Department of Information Medicine, Asan Medical Center, Seoul, Korea
}

\begin{abstract}
Objective. Previous studies investigating the beneficial effect of rituximab on lupus nephritis (LN) reported controversial results. There have been few reports of renal response to rituximab according to renal function. We investigated the efficacy of rituximab in refractory/relapsing LN and the role of renal function as a predictor of renal response. Methods. From 2016 to 2019 , we retrospectively reviewed 22 patients with refractory/relapsing LN receiving rituximab. Renal responses (complete and partial) at 6 and 12 months were compared between normal (glomerular filtration rate [GFR] $\geq 90 \mathrm{~mL} / \mathrm{min} / 1.73 \mathrm{~m}^{2}, \mathrm{n}=11$ ) and decreased (GFR $<90 \mathrm{~mL} / \mathrm{min} / 1.73 \mathrm{~m}^{2}, \mathrm{n}=11$ ) GFR groups. Multivariate Cox regression analysis was used to assess predictors of renal response. Results. At baseline, the decreased GFR group had a higher urine proteinuria to creatinine ratio $(p=0.008)$ and proportion of refractory LN $(p=0.010)$ and previous cyclophosphamide therapy $(p=0.035)$ than the normal GFR group. The overall renal response rate was $45.5 \%$ (10 patients) at 6 months and $54.5 \%$ (12 patients) at 12 months. Renal response rates were higher in the normal GFR group $(81.8 \%$ and $90.9 \%$ at 6 and 12 months, respectively) than in the decreased GFR group $(9.1 \%$ and $18.2 \%$ at 6 and 12 months, respectively; $p<0.001)$. Normal GFR and anti-La were associated with renal response to rituximab, with hazard ratios of $9.256(p=0.008)$ and $5.478(p=0.041)$, respectively. Conclusion. Rituximab is an effective therapy for refractory/relapsing LN, particularly in patients with preserved renal function. (J Rheum Dis 2022;29:22-32)
\end{abstract}

Key Words. Lupus nephritis, Systemic lupus erythematosus, Kidney, Rituximab, Glomerular filtration rate

\section{INTRODUCTION}

Lupus nephritis (LN) is a major organ involvement complication of systemic lupus erythematosus (SLE) and occurs in up to $60 \%$ of patients with SLE. The current treatment regimen for $\mathrm{LN}$ is a combination of corticosteroids and immunosuppressants, including cyclophosphamide (CYC), mycophenolate mofetil (MMF), and tacrolimus. However, only $50 \% \sim 70 \%$ of patients achieve remission, whereas the rest do not achieve remission or experience a relapse [1,2]. Eventually, $10 \%$ to $30 \%$ of patients progress to end-stage renal disease (ESRD). These poor outcomes of LN warrant new therapeutic agents, but to date, there is no standard treatment for refractory or relapsing LN.

B cells play crucial roles in the pathogenesis of SLE through autoantibody production, presentation of autoantigens to T cells, and cytokine production [3]. Rituximab is a chimeric monoclonal CD20 antibody that is effective in rheumatoid arthritis and antineutrophil cytoplasmic antibody-associated vasculitis [4,5]. However, the effects of rituximab on SLE are debated, and further research is required [6-9]. Discrepancies between randomized controlled trials and other observational studies require us to focus on the factors associated with renal response to rituximab. Several prognostic factors for $\mathrm{LN}$ have been

Received : May 10, 2021, Revised : July 22, 2021, Accepted : August 13, 2021

Corresponding to : Yong-Gil Kim iD http://orcid.org/0000-0002-8029-7355

Department of Rheumatology, Asan Medical Center, University of Ulsan College of Medicine, 88 Olympic-ro 43-gil, Songpa-gu, Seoul 05505, Korea. E-mail : bestmd2000@amc.seoul.kr 
studied, including proteinuria, renal function, serologic markers, and pathological class [10,11]. However, few studies have reported the efficacy of rituximab in LN according to renal function. Therefore, the aim of the present study was to evaluate the effectiveness of rituximab in refractory or relapsing $\mathrm{LN}$ and determine whether or not renal function is useful in predicting renal response to rituximab.

\section{MATERIALS AND METHODS}

\section{Study population}

We enrolled 22 adult patients with refractory or relapsing LN who had been started on rituximab from January 2016 to December 2019 at a tertiary referral hospital in South Korea. They were diagnosed with LN according to the International Society of Nephrology/Renal Pathology Society (ISN/RPS) 2003 classification [12]. Refractory $\mathrm{LN}$ was defined as an inadequate renal response after standard immunosuppressive therapy including CYC and MMF. Patients were followed-up for 12 months after rituximab therapy. Those with renal replacement treatment were excluded. This study was conducted in accordance with the principles of the Declaration of Helsinki. The Institutional Review Board of the Asan Medical Center approved this study (IRB number: 2020-0184) and waived the requirement for informed consent because of the retrospective study design.

\section{Data collection}

We retrospectively reviewed the electronic medical records of patients for age, sex, SLE and LN durations, medications, and the SLE Disease Activity Index-2K (SLEDAI-2K) score. We collected laboratory data, including the serum creatinine level, glomerular filtration rate (GFR), urine protein to creatinine ratio (UPCR), presence/absence of hematuria, serum albumin level, complement level, and anti-double-stranded DNA antibody (anti-dsDNA) level. Renal pathology was reviewed to measure the activity and chronicity indexes. We estimated GFR using the Chronic Kidney Disease Epidemiology Collaboration equation. Sequential serological and urinary data were also documented at 3, 6, and 12 months. Patients were classified into two groups according to GFR at the start of rituximab therapy: normal (GFR $\geq 90$ $\mathrm{mL} / \mathrm{min} / 1.73 \mathrm{~m}^{2}$ ) and decreased (GFR $<90 \mathrm{~mL} / \mathrm{min} /$ $1.73 \mathrm{~m}^{2}$ ) GFR groups.

\section{Renal outcome}

Renal response was defined as the achievement of complete or partial renal response. Complete renal response (CR) was defined as a UPCR $<500 \mathrm{mg} / \mathrm{g}$ and normal or stable GFR (within $10 \%$ change in GFR if previously abnormal) $[13,14]$. Partial renal response (PR) was defined as a $\geq 50 \%$ reduction of UPCR to subnephrotic levels and normal or stable GFR. The responder was defined as a patient who achieved a renal response. Relapse was defined as reproducible doubling of UPCR to $>1,000 \mathrm{mg} / \mathrm{g}$ after CR or to $>2,000 \mathrm{mg} / \mathrm{g}$ after PR [15]. Changes in clinical parameters from baseline to 3,6 , and 12 months were also evaluated.

\section{Statistical analysis}

Continuous variables are expressed as median (interquartile range $[\mathrm{IQR}])$. They were compared using the Mann-Whitney U-test. Categorical data are expressed as number (percentage). They were analyzed using the chi-squared test and Fisher's exact test. Wilcoxon signed-rank test was used to compare paired clinical parameters within the two groups at different time points. We performed Kaplan-Meier analysis with the log-rank test to assess the cumulative renal response rates. Univariate and multivariate Cox proportional hazard analyses with a stepwise method were conducted to calculate the hazard ratio (HR) and $95 \%$ confidence interval (CI) for renal response to rituximab. Variables with a p-value $<0.2$ in the univariate Cox analysis were included in the multivariate Cox analysis. A p-value $<0.05$ was considered to be statistically significant in other analyses.

\section{RESULTS}

\section{Baseline characteristics and treatment regimen in normal and decreased GFR groups}

We enrolled a total of 22 patients with LN, including 2 (9.1\%) male and 20 (90.9\%) female, with a median age of 39 (IQR, 24 50) years. The median SLE and LN durations were 10.7 (IQR, 6.4 17.8) and 5.8 (IQR, 3.2 8.6) years, respectively. The ISN/RPS classification was class III in $11(50 \%)$ patients, class IV in 10 (45.5\%) patients, and pure class $\mathrm{V}$ in one (4.5\%) patient. In 19 patients with the activity and chronicity indexes, the median scores were 6 (IQR, $5 \sim 10$ ) and 3 (IQR, $1 \sim 4$ ), respectively. Ten cases were refractory, whereas the others were relapsing. Eleven patients showed normal GFR levels at the start of rituximab therapy, whereas the remaining 11 patients 
Su Jin Choi et al.

Table 1. Baseline characteristics of patients in normal and decreased glomerular filtration rate groups

\begin{tabular}{|c|c|c|c|}
\hline Variable & Normal GFR $(n=11)$ & Decreased GFR $(n=11)$ & p-value \\
\hline Age (yr) & $31(24 \sim 49)$ & $43(24 \sim 56)$ & 0.300 \\
\hline Female & $10(90.9)$ & $10(90.9)$ & 1.000 \\
\hline Duration since SLE diagnosis (yr) & $12.4(3.2 \sim 18.3)$ & $8.7(6.8 \sim 15.4)$ & 1.000 \\
\hline Duration since LN diagnosis (yr) & $5.7(2.4 \sim 8.1)$ & $5.8(4.2 \sim 10.1)$ & 0.519 \\
\hline Duration since last kidney biopsy (yr) & $2.7(1.0 \sim 6.4)$ & $5.8(3.3 \sim 10.1)$ & 0.116 \\
\hline \multicolumn{4}{|l|}{ ISN/RPS classification } \\
\hline Class III & $6(54.5)$ & $5(45.5)$ & 0.670 \\
\hline Class IV & $4(36.4)$ & $6(54.5)$ & 0.392 \\
\hline Pure class V & $1(9.1)$ & $0(0)$ & 1.000 \\
\hline Class III/V & $1(9.1)$ & $2(18.2)$ & 1.000 \\
\hline Class IV/V & $0(0)$ & $2(18.2)$ & 0.476 \\
\hline Activity index & $6(3 \sim 9)$ & $8(5 \sim 11)^{*}$ & 0.492 \\
\hline Chronicity index & $2(1 \sim 4)$ & $4(2 \sim 5)^{*}$ & 0.310 \\
\hline Refractory LN & $2(18.2)$ & $8(72.7)$ & 0.010 \\
\hline \multicolumn{4}{|l|}{ Previous immunosuppressants } \\
\hline Cyclophosphamide & $6(54.5)$ & $11(100)$ & 0.035 \\
\hline Mycophenolate mofetil & $11(100)$ & $10(90.9)$ & 1.000 \\
\hline Azathioprine & $7(63.6)$ & $7(63.6)$ & 1.000 \\
\hline Tacrolimus & 9 (81.8) & $11(100)$ & 0.476 \\
\hline Hydroxychloroquine & $11(100)$ & $11(100)$ & $N / A$ \\
\hline \multicolumn{4}{|c|}{ Immunosuppressants before the start of rituximab } \\
\hline Cyclophosphamide & $0(0)$ & $4(36.4)$ & 0.090 \\
\hline Mycophenolate mofetil & $8(72.7)$ & $4(36.4)$ & 0.087 \\
\hline Azathioprine & $1(9.1)$ & $0(0)$ & 1.000 \\
\hline Tacrolimus & $7(63.6)$ & $3(27.3)$ & 0.087 \\
\hline Hydroxychloroquine & $11(100)$ & $7(63.6)$ & 0.090 \\
\hline Glucocorticoid treatment & $8(72.7)$ & $8(72.7)$ & 1.000 \\
\hline Prednisolone dose (mg/day) & $5.0(0 \sim 20.0)$ & $7.5(0 \sim 20.0)$ & 0.949 \\
\hline \multicolumn{4}{|l|}{ Rituximab regimen } \\
\hline $1,000 \mathrm{mg} \times 2$ infusions & $10(90.9)$ & $6(54.5)$ & 0.149 \\
\hline $500 \mathrm{mg} \times 4$ infusions & $1(9.1)$ & $3(27.3)$ & 0.586 \\
\hline $500 \mathrm{mg} \times 3$ infusions & $0(0)$ & $1(9.1)$ & 1.000 \\
\hline $500 \mathrm{mg} \times 2$ infusions & $0(0)$ & $1(9.1)$ & 1.000 \\
\hline \multicolumn{4}{|l|}{ Laboratory finding } \\
\hline Serum creatinine (mg/dL) & $0.70(0.48 \sim 0.75)$ & $1.59(0.97 \sim 2.15)$ & $<0.001$ \\
\hline $\operatorname{GFR}\left(\mathrm{mL} / \mathrm{min} / 1.73 \mathrm{~m}^{2}\right)$ & $116(101 \sim 123)$ & $39(27 \sim 79)$ & $<0.001$ \\
\hline UPCR (mg/g) & $1,275(920 \sim 2,199)$ & $3,110(2,264 \sim 5,682)$ & 0.008 \\
\hline UPCR $<1,000 \mathrm{mg} / \mathrm{g}$ & $4(36.4)$ & $0(0)$ & 0.090 \\
\hline UPCR $\geq 3,000 \mathrm{mg} / \mathrm{g}$ & $2(18.2)$ & $7(63.6)$ & 0.080 \\
\hline Microscopic hematuria & $5(45.5)$ & $4(36.4)$ & 1.000 \\
\hline Serum albumin (g/dL) & $3.1(2.8 \sim 3.4)$ & $3.2(1.9 \sim 3.6)$ & 0.748 \\
\hline $\mathrm{C} 3(\mathrm{mg} / \mathrm{dL})$ & $52.1(41.9 \sim 90.7)$ & $76.2(38.7 \sim 109.0)$ & 0.438 \\
\hline $\mathrm{C} 4(\mathrm{mg} / \mathrm{dL})$ & $9.8(4.5 \sim 15.1)$ & $22.1(14.6 \sim 25.2)$ & 0.007 \\
\hline Anti-dsDNA titer (IU/mL) & $47.7(7.2 \sim 488.0)$ & $11.9(3.5 \sim 33.8)$ & 0.401 \\
\hline \multicolumn{4}{|l|}{ Anti-ENA positivity } \\
\hline Anti-Ro & $7 / 10(70)$ & $5 / 11(45.5)$ & 0.387 \\
\hline Anti-RNP & $6 / 10(60)$ & 4/11 (36.4) & 0.395 \\
\hline Anti-Sm & $4 / 10(40)$ & $4 / 11(36.4)$ & 1.000 \\
\hline Anti-La & $2 / 10(20)$ & $1 / 11(9.1)$ & 0.586 \\
\hline SLEDAI-2K score & $12(6 \sim 16)$ & $8(6 \sim 16)$ & 0.606 \\
\hline
\end{tabular}

Data are expressed as median (interquartile range) or number (\%). GFR: glomerular filtration rate, SLE: systemic lupus erythematosus, LN: lupus nephritis, ISN/RPS: International Society of Nephrology/Renal Pathology Society, UPCR: urine protein to creatinine ratio, SLEDAI-2K: Systemic Lupus Erythematosus Disease Activity Index 2000, N/A: not available. *Three patients were excluded because of missing data. 
had decreased GFR levels. Among them, 8 patients had GFR $<60 \mathrm{~mL} / \mathrm{min} / 1.73 \mathrm{~m}^{2}$ at baseline.

We compared the baseline characteristics of patients between normal and decreased GFR groups (Table 1). The decreased GFR group showed higher proportions of refractory LN $(72.7 \%$ vs. $18.2 \%, \mathrm{p}=0.010)$ and previous CYC therapy ( $100 \%$ vs. $54.5 \%, \mathrm{p}=0.035)$ than the normal GFR group. At the start of rituximab therapy, the median serum creatinine level was 0.70 (IQR, $0.48 \sim 0.75) \mathrm{mg} / \mathrm{dL}$ in the normal GFR group and 1.59 (IQR, 0.97 2.15) $\mathrm{mg} / \mathrm{dL}$ in the decreased GFR group; the median GFR level was 116 (IQR, 101 123) $\mathrm{mL} / \mathrm{min} / 1.73 \mathrm{~m}^{2}$ in the normal GFR group and 39 (IQR, 27 79) $\mathrm{mL} / \mathrm{min} / 1.73 \mathrm{~m}^{2}$ in the decreased GFR group. The median UPCR level was higher in the decreased GFR group than in the normal GFR group $(3,110$ [IQR, 2,264 5,682] mg/g vs. 1,275 [IQR, $920 \sim 2,199] \mathrm{mg} / \mathrm{g}, \mathrm{p}=0.008$ ). There was no significant difference between the two groups in the proportion of patients with UPCR $<1,000$ or $\geq 3,000 \mathrm{mg} / \mathrm{g}$. The minimum UPCR level was $896 \mathrm{mg} / \mathrm{g}$ in the entire study population. The median $\mathrm{C} 4$ level was lower in the normal GFR group than in the decreased GFR group $(9.8$ [IQR, $4.5 \sim 15.1] \mathrm{mg} / \mathrm{dL}$ vs. $22.1[\mathrm{IQR}, 14.6 \sim 25.2] \mathrm{mg} / \mathrm{dL}$, $\mathrm{p}=0.007$ ). Other laboratory findings, including anti-dsDNA titers, anti-ENA positivity, or the SLEDAI-2K score, did not differ between the groups.

Table 2 shows concomitant treatment with rituximab therapy. MMF was used in $54.5 \%$ of patients during $0 \sim 6$ months and $63.6 \%$ of patients during 6 12 months. Both groups received almost similar treatments during the follow-up. For $6 \sim 12$ months, tacrolimus was used more in the normal GFR group than in the decreased GFR group ( $81.8 \%$ vs. $27.3 \%, p=0.030)$. Rituximab was re-administrated during 6 12 months to one patient in the normal GFR group and one patient in the decreased GFR group.

\section{Renal response to rituximab in normal and decreased GFR groups}

The overall renal response was achieved in 10 patients (CR, eight patients; PR, two patients) at 6 months and 12 patients (all CR) at 12 months. When comparing the treatment regimens of responders (12 patients) and non-responders (10 patients) up to the date of response or last follow-up, there was no difference in the median cumulative dose of rituximab $(2,000$ [IQR, 2,000 $2,000] \mathrm{mg}$ vs. 2,000 [IQR, 1,875 2,000] mg, $\mathrm{p}=0.456$ ) and prednisolone $(8.2[5.0 \sim 18.0] \mathrm{mg} /$ day vs. $6.4[0.8 \sim$ $12.7] \mathrm{mg} /$ day, $\mathrm{p}=0.539$ ). The proportion of patients who had ever been treated with prednisolone $\geq 30 \mathrm{mg} /$ day did not differ between the two groups (responder vs. non-responder, $25.0 \%$ vs. $30.0 \%, \mathrm{p}=1.000$ ). The proportion of patients with concomitant treatment including CYC ( $8.3 \%$ vs. $10.0 \%, p=1.000)$, MMF $(50.0 \%$ vs. $60.0 \%$, $\mathrm{p}=0.691)$, azathioprine ( $8.3 \%$ vs. $0 \%, \mathrm{p}=1.000)$, tacrolimus $(58.3 \%$ vs. $50.0 \%, \mathrm{p}=1.000)$, and hydroxychloroquine

Table 2. Concomitant treatment after rituximab therapy in normal and decreased glomerular filtration rate groups

\begin{tabular}{lccc}
\hline \multicolumn{1}{c}{ Variable } & Normal GFR $(\mathrm{n}=11)$ & Decreased GFR $(\mathrm{n}=11)$ & $\mathrm{p}$-value \\
\hline $0 \sim 6$ months & & & 1.000 \\
Cyclophosphamide & $1(9.1)$ & $0(0)$ & 0.087 \\
Mycophenolate mofetil & $8(72.7)$ & $1(36.4)$ & 1.000 \\
Azathioprine & $1(9.1)$ & $4(36.4)$ & 0.087 \\
Tacrolimus & $8(72.7)$ & $8(72.7)$ & 0.214 \\
Hydroxychloroquine & $11(100)$ & $8(72.7)$ & 1.000 \\
Glucocorticoid & $9(81.8)$ & $6.2(0 \sim 12.4)$ & 0.606 \\
Prednisolone dose (mg/day) & $7.9(0.4 \sim 12.7)$ & $0(0)$ & $\mathrm{N} / \mathrm{A}$ \\
Re-infusion of rituximab & $0(0)$ & $1(9.1)$ & 1.000 \\
6 12 months & $0(0)$ & $5(45.5)$ & 0.183 \\
Cyclophosphamide & $9(81.8)$ & $1(9.1)$ & 1.000 \\
Mycophenolate mofetil & $1(9.1)$ & $3(27.3)$ & 0.030 \\
Azathioprine & $9(81.8)$ & $8(72.7)$ & 0.214 \\
Tacrolimus & $11(100)$ & $8(72.7)$ & 1.000 \\
Hydroxychloroquine & $8(72.7)$ & $2.9(0 \sim 11.4)$ & 0.562 \\
Glucocorticoid & $5.8(0 \sim 14.5)$ & $1(9.1)$ & 1.000 \\
Prednisolone dose (mg/day) & $1(9.1)$ & & \\
Re-infusion of rituximab & & & \\
\hline
\end{tabular}

Data are expressed as median (interquartile range) or number (\%). GFR: glomerular filtration rate, N/A: not available. 
( $83.3 \%$ vs. $70.0 \%, \mathrm{p}=0.624)$ was also similar between the two groups.

In the normal GFR group, renal response was achieved in nine patients (CR, eight patients; PR, one patient) at 6 months and 10 patients (all CR) at 12 months. In the decreased GFR group, renal response was achieved in one patient (PR) at 6 months and two patients (all CR) at 12 months. Among nine patients with UPCR $\geq 3,000 \mathrm{mg} / \mathrm{g}$, renal response was reported in one of two (50\%) patients in the normal GFR group and one of seven (14.3\%) patients in the decreased GFR group during 12 months. Among nine patients with $3,000 \mathrm{mg} / \mathrm{g}>\mathrm{UPCR} \geq 1,000$ $\mathrm{mg} / \mathrm{g}$, renal response was achieved in five of five (100\%) patients in the normal GFR group and one of four (25\%) patients in the decreased GFR group. Four patients with UPCR $<1,000 \mathrm{mg} / \mathrm{g}$ were in the normal GFR group and achieved renal response.

The overall cumulative renal response rate was $45.5 \%$ at 6 months and $54.5 \%$ at 12 months (Figure 1). The overall CR rate was $36.4 \%$ at 6 months and $54.5 \%$ at 12 months. When assessed according to the GFR groups, the cumulative renal response rates at 6 and 12 months were $81.8 \%$ and $90.9 \%$ in the normal GFR group, respectively, and $9.1 \%$ and $18.2 \%$ in the decreased GFR group, respectively. Cumulative CR rates at 6 and 12 months were $72.7 \%$ and $90.9 \%$ in the normal GFR group, respectively, and $0 \%$ and $18.2 \%$ in the decreased GFR group, respectively. The normal GFR group showed a higher renal response rate than the decreased GFR group (log-rank test, $\mathrm{p}<0.001$ ). Two patients in the normal GFR group experienced relapse at 6 months. One of them showed improvement after re-in-

A

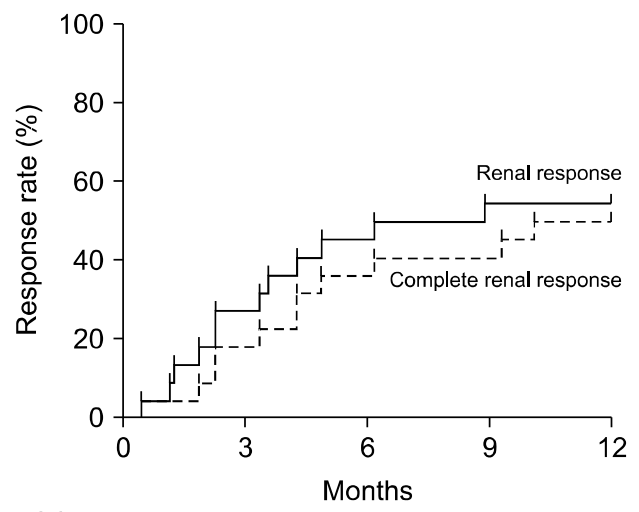

Number at risk:

$\begin{array}{llllll}\text { Renal response } & 22 & 16 & 12 & 10 & 10\end{array}$ Complete response 22

$\begin{array}{llll}16 & 12 & 10 & 10 \\ 18 & 14 & 13 & 11\end{array}$

fusion of rituximab at 3 months after relapse.

Figure 2 shows changes in clinical parameters from baseline to 12 months in both groups. The median UPCR level had significantly decreased at 12 months in both groups (normal GFR group, from 1,275 [IQR, 920 2,199] to 380 [IQR, 120 426] mg/g, p=0.003; decreased GFR group, from 3,110 [IQR, 2,264 5,682] to 1,992 [IQR, 780 3,543] mg/g, $\mathrm{p}=0.026$ ). The median GFR level changed from 116 [IQR, 101 123] to 109 [IQR, $86 \sim 111] \mathrm{mL} / \mathrm{min} / 1.73 \mathrm{~m}^{2}$ at 12 months in the normal GFR group $(\mathrm{p}=0.041)$. However, the decreased GFR group exhibited no significant change in the median GFR level from 39 (IQR, 27 79) to 33 (IQR, 22 68) $\mathrm{mL} / \mathrm{min} / 1.73 \mathrm{~m}^{2}$ at 12 months. The median serum albumin level increased in both groups at 12 months (normal GFR group, from 3.1 to $3.7 \mathrm{~g} / \mathrm{dL}, \mathrm{p}=0.003$; decreased GFR group, from 3.2 to $3.5 \mathrm{~g} / \mathrm{dL}, \mathrm{p}=0.015)$. The median SLEDAI-2K score had decreased at 12 months in the normal GFR group (from 12 [IQR, 6 16] to 4 [IQR, 2 6], $\mathrm{p}=0.005$ ), but not in the decreased GFR group (from 8 [IQR, 6 16] to 8 [IQR, 6 12], $\mathrm{p}=0.497$ ). The normal GFR group also showed improved C3, C4, and anti-dsDNA titers at 12 months.

\section{Predictors of renal response to rituximab}

The Cox proportional hazard regression analysis of renal response to rituximab was performed (Table 3). In the univariate Cox regression analysis, the normal GFR level $(\mathrm{HR}=11.331 ; 95 \% \mathrm{CI}: 2.305 \sim 55.710 ; \mathrm{p}=0.003), \mathrm{GFR} \geq$ $60 \mathrm{~mL} / \mathrm{min} / 1.73 \mathrm{~m}^{2}$ (HR=9.534; 95\% CI: $1.215 \sim$ 74.823; $\mathrm{p}=0.032)$, and positive anti-La $(\mathrm{HR}=10.406$;

B

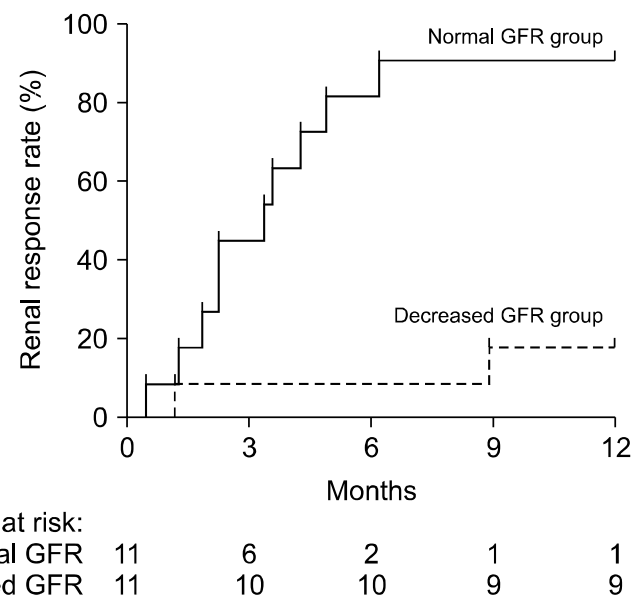

Figure 1. Kaplan-Meier curves for (A) the renal response rate in all patients and (B) renal response rates in normal and decreased glomerular filtration rate groups. Renal response was defined as the achievement of complete or partial renal response. GFR: glomerular filtration rate. 

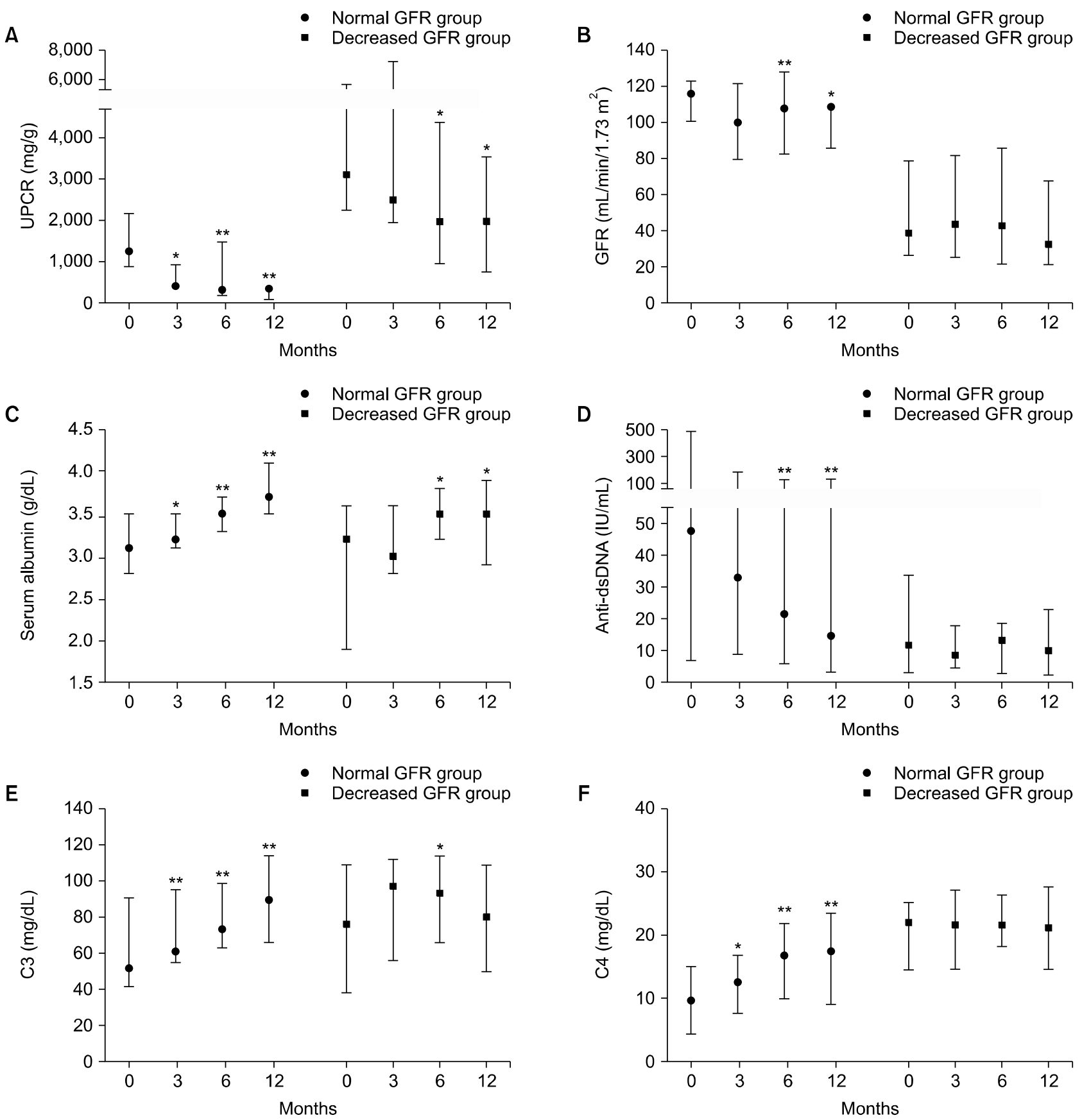

Figure 2. Changes in clinical parameters in normal and decreased glomerular filtration rate groups. (A) Urine protein to creatinine ratio (UPCR). (B) Glomerular filtration rate (GFR). (C) Serum albumin. (D) Anti-dsDNA titer. (E) C3. (F) C4. Data are expressed as median (interquartile range). Wilcoxon signed-rank test was used to assess the changes in parameters from baseline within each group $(* \mathrm{p}<0.05, * * \mathrm{p}<0.01)$.

95\% CI: 2.010 53.878; $\mathrm{p}=0.005)$ were associated with renal response to rituximab. The levels of C3 $(\mathrm{HR}=0.976$; 95\% CI: 0.954 0.999; $\mathrm{p}=0.038)$ and the history of CYC therapy $(\mathrm{HR}=0.221 ; 95 \% \mathrm{CI}: 0.063 \sim 0.780 ; \mathrm{p}=0.019)$ negatively correlated with renal response to rituximab. The multivariate Cox regression analysis revealed that the normal GFR level $(\mathrm{HR}=9.256 ; 95 \% \mathrm{CI}: 1.767 \sim$
48.481; $\mathrm{p}=0.008)$ and positive anti-La $(\mathrm{HR}=5.478 ; 95 \%$ CI: $1.072 \sim 27.992 ; \mathrm{p}=0.041)$ were statistically significant predictors of renal response to patients with refractory or relapsing LN treated with rituximab. 
Table 3. Univariate and multivariate Cox regression analyses for predictors of renal response

\begin{tabular}{|c|c|c|c|c|c|c|}
\hline \multirow{2}{*}{ Variable } & \multicolumn{3}{|c|}{ Univariate analysis } & \multicolumn{3}{|c|}{ Multivariate analysis } \\
\hline & $\mathrm{HR}$ & $95 \% \mathrm{Cl}$ & p-value & $\mathrm{HR}$ & $95 \% \mathrm{Cl}$ & p-value \\
\hline Age (yr) & 0.986 & $0.947 \sim 1.026$ & 0.485 & & & \\
\hline Female & 1.487 & $0.191 \sim 11.564$ & 0.705 & & & \\
\hline Duration since SLE diagnosis (yr) & 1.016 & $0.936 \sim 1.103$ & 0.704 & & & \\
\hline Duration since LN diagnosis (yr) & 0.969 & $0.866 \sim 1.085$ & 0.588 & & & \\
\hline \multicolumn{7}{|l|}{ ISN/RPS classification } \\
\hline Class III & 1.566 & $0.495 \sim 4.956$ & 0.446 & & & \\
\hline Class IV & 0.475 & $0.142 \sim 1.588$ & 0.227 & & & \\
\hline Class III/V or IV/V & 0.215 & $0.028 \sim 1.671$ & 0.142 & & & \\
\hline Activity index* & 0.899 & $0.760 \sim 1.062$ & 0.210 & & & \\
\hline Chronicity index* & 0.905 & $0.690 \sim 1.186$ & 0.468 & & & \\
\hline Refractory LN (vs. relapsing LN) & 0.291 & $0.078 \sim 1.083$ & 0.066 & & & \\
\hline \multicolumn{7}{|l|}{ Previous immunosuppressants } \\
\hline Cyclophosphamide & 0.221 & $0.063 \sim 0.780$ & 0.019 & & & \\
\hline Mycophenolate mofetil & 22.295 & $0.001 \sim 661,999.761$ & 0.555 & & & \\
\hline Azathioprine & 2.061 & $0.557 \sim 7.626$ & 0.279 & & & \\
\hline Tacrolimus & 0.346 & $0.071 \sim 1.676$ & 0.187 & & & \\
\hline \multicolumn{7}{|c|}{ Immunosuppressants before the start of rituximab } \\
\hline Cyclophosphamide & 0.367 & $0.047 \sim 2.858$ & 0.339 & & & \\
\hline Mycophenolate mofetil & 1.676 & $0.503 \sim 5.584$ & 0.400 & & & \\
\hline Azathioprine & 2.995 & $0.360 \sim 24.917$ & 0.310 & & & \\
\hline Tacrolimus & 1.791 & $0.567 \sim 5.654$ & 0.320 & & & \\
\hline Hydroxychloroquine & 2.722 & $0.350 \sim 21.175$ & 0.339 & & & \\
\hline Baseline prednisolone dose (mg/day) & 1.003 & $0.972 \sim 1.034$ & 0.872 & & & \\
\hline \multicolumn{7}{|l|}{ Baseline laboratory findings } \\
\hline Normal GFR level & 11.331 & $2.305 \sim 55.710$ & 0.003 & 9.256 & $1.767 \sim 48.481$ & 0.008 \\
\hline $\mathrm{GFR} \geq 60 \mathrm{~mL} / \mathrm{min} / 1.73 \mathrm{~m}^{2}$ & 9.534 & $1.215 \sim 74.823$ & 0.032 & & & \\
\hline UPCR (mg/g) & 1.000 & $0.999 \sim 1.000$ & 0.174 & & & \\
\hline Microscopic hematuria & 1.285 & $0.407 \sim 4.061$ & 0.669 & & & \\
\hline Serum albumin $(\mathrm{g} / \mathrm{dL})$ & 0.829 & $0.379 \sim 1.814$ & 0.640 & & & \\
\hline $\mathrm{C} 3(\mathrm{mg} / \mathrm{dL})$ & 0.976 & $0.954 \sim 0.999$ & 0.038 & & & \\
\hline $\mathrm{C} 4(\mathrm{mg} / \mathrm{dL})$ & 0.938 & $0.874 \sim 1.007$ & 0.075 & & & \\
\hline Anti-dsDNA titer (IU/mL) & 1.000 & $0.999 \sim 1.001$ & 0.921 & & & \\
\hline \multicolumn{7}{|l|}{ Anti-ENA positivity $^{\dagger}$} \\
\hline Anti-RNP & 1.857 & $0.564 \sim 6.114$ & 0.309 & & & \\
\hline Anti-Sm & 1.155 & $0.337 \sim 3.957$ & 0.819 & & & \\
\hline Anti-Ro & 2.701 & $0.709 \sim 10.292$ & 0.145 & & & \\
\hline Anti-La & 10.406 & $2.010 \sim 53.878$ & 0.005 & 5.478 & $1.072 \sim 27.992$ & 0.041 \\
\hline Baseline SLEDAI-2K score & 1.019 & $0.915 \sim 1.135$ & 0.729 & & & \\
\hline \multicolumn{7}{|l|}{ Concomitant treatment } \\
\hline Cyclophosphamide & 0.673 & $0.086 \sim 5.232$ & 0.705 & & & \\
\hline Mycophenolate mofetil & 0.715 & $0.230 \sim 2.228$ & 0.563 & & & \\
\hline Azathioprine & 2.995 & $0.360 \sim 24.917$ & 0.310 & & & \\
\hline Tacrolimus & 1.253 & $0.397 \sim 3.957$ & 0.701 & & & \\
\hline Cumulative dose of prednisolone (mg/day) & 1.035 & $0.969 \sim 1.106$ & 0.307 & & & \\
\hline
\end{tabular}

HR: hazard ratio, Cl: confidence interval, SLE: systemic lupus erythematosus, LN: lupus nephritis, ISN/RPS: International Society of Nephrology/Renal Pathology Society, GFR: glomerular filtration rate, UPCR: urine protein to creatinine ratio, SLEDAI-2K: Systemic Lupus Erythematosus Disease Activity Index 2000. ${ }^{*}$ Three patients were excluded because of missing data. ${ }^{\dagger}$ One patient was excluded because of missing data.

\section{DISCUSSION}

We demonstrated that half of the patients treated with rituximab achieved renal response in refractory or relapsing LN. Patients with normal renal function, defined as GFR $\geq 90 \mathrm{~mL} / \mathrm{min} / 1.73 \mathrm{~m}^{2}$, showed better renal re- 
sponse to rituximab than those with impaired renal function. Most clinical parameters, including proteinuria, improved with 12 months of treatment; however, GFR did not recover. This study suggested that rituximab is a beneficial therapeutic agent in refractory or relapsing $\mathrm{LN}$, particularly when renal function is preserved within the normal range.

The efficacy of rituximab in $\mathrm{LN}$ has been investigated in previous studies. The randomized controlled study, Lupus Nephritis Assessment with Rituximab (LUNAR) trial, did not meet the primary endpoint and failed to demonstrate the role of rituximab as an add-on therapy in LN [6]. However, although statistically insignificant, the rituximab group had a 15\% increased PR rate compared to the placebo group and reported positive results in terms of proteinuria responses and serologic markers. Several LN studies revealed that rituximab induction and MMF maintenance treatment were effective with the steroid-sparing effect $[16,17]$. In a study of pathological changes in LN after rituximab therapy, most patients who underwent repeat biopsy after rituximab therapy showed histological transition into a more favorable type with a decreased renal activity index score [18]. These pathologic improvements in LN have been reported in other rituximab studies $[19,20]$. B lymphocyte depletion occurs after rituximab therapy and is associated with renal response $[21,22]$. The effects of rituximab on regulatory cells and apoptosis of $\mathrm{T}$ lymphocytes in $\mathrm{LN}$ have been reported [23]. These clinical, pathological, and immunological results, which differ from randomized controlled trial results, require us to focus on factors associated with renal response to rituximab.

Several previous studies have shown that rituximab may be an alternative therapy in refractory or relapsing $L N$ [7,24-26]. Based on these results, the 2019 Joint European League Against Rheumatism and European Renal Association-European Dialysis and Transplant Association guideline recommend rituximab for active non-responding/refractory LN cases [27]. Ethnicity may also affect renal response to rituximab in LN. The prevalence of LN was higher in Asians than in Caucasians, whereas 10-year renal outcomes were better in Asians [28]. The LUNAR trial showed a tendency of improved renal outcomes in Africans compared to individuals of other ethnicities [6]. We reported that $54.5 \%$ of Koreans with refractory or relapsing $\mathrm{LN}$ achieved renal response in 12 months of rituximab therapy. This result was consistent with a multicenter retrospective study in Korean patients with SLE, which showed a renal response rate of $65 \%$ to rituximab at 6 months [29]. Similarly, a study of Japanese patients with refractory $\mathrm{LN}$ reported that $58.8 \%$ of patients treated with rituximab achieved a renal response [30]. We suggested the beneficial effects of rituximab in East Asians with refractory or relapsing LN.

As for other clinical information related to the treatment response to rituximab, a pooled analysis study from European cohorts showed that nephrotic syndrome and renal failure at the time of rituximab administration were reported more frequently in patients with no achievement of CR than in those with CR [31]. GFR may be a candidate for predicting renal response to rituximab in LN. GFR and proteinuria are components of LN treatment goals. Proteinuria changes earlier and greater after treatment, whereas GFR changes later in some cases [32]. In a study on renal function as a predictor of LN, patients with GFR $<60 \mathrm{~mL} / \mathrm{min} / 1.73 \mathrm{~m}^{2}$ showed poor renal outcomes, including ESRD [33]. Dall'Era et al. [34] described that the baseline GFR level predicted renal response to MMF or CYC at 6 months. However, the role of GFR in predicting renal outcome is reported inconsistently. Haridasan et al. [35] found that $70.7 \%$ of patients with GFR $<30 \mathrm{~mL} / \mathrm{min}$ at presentation had good renal response without persistent low GFR or ESRD for 1 year, indicating that renal outcomes may be favorable even in patients with severe renal function. In studies on the efficacy of MMF as induction and maintenance therapy, patients with baseline renal impairment (GFR $<60 \mathrm{~mL}$ / $\min / 1.73 \mathrm{~m}^{2}$ ) had similar renal responses and relapse rates compared to patients with normal renal function $[36,37]$. In our study, the normal GFR group had better renal responses after rituximab therapy than the decreased GFR group. The multivariate Cox analysis showed that normal renal function at the start of rituximab therapy was associated with the achievement of renal response in patients with refractory or relapsing $\mathrm{LN}$ treated with rituximab. The normal GFR group also improved markers of lupus activity, including SLEDAI-2K score, C3, C4, and anti-dsDNA titers. Moreover, our results were supported by a previous LN study, reporting that baseline GFR $<30 \mathrm{~mL} / \mathrm{min}$ was observed more frequently in renal non-responders than in responders after rituximab treatment [38].

There have been several challenges in the effective use of rituximab in $\mathrm{LN}$, including combination with other immunosuppressants. Zhang et al. [39] showed that combination therapy of rituximab and CYC might be 
more beneficial than CYC monotherapy. The combination of rituximab and belimumab also seems a promising treatment to improve lupus activity, with the synergistic effects of B cell depletion and BAFF inhibition [40]. In contrast, a randomized pilot study on the efficacy of rituximab in LN did not prove the improvement of renal response with the addition of CYC [41]. In our study, there were no beneficial effects of combination or sequential therapy with other immunosuppressants. As for the treatment of relapse after rituximab therapy in LN, re-administration of rituximab may help to achieve a good response again. Pepper et al. [16] reported B cell reconstitution in relapsed patients after rituximab therapy. In a study of rituximab therapy in SLE, one patient who experienced recurrence after rituximab therapy had a good response with re-administration of rituximab [42]. We also reported one relapsed patient who had a good renal response with re-administration of rituximab, supporting previous results.

The preferred schedule of rituximab therapy is $1,000 \mathrm{mg}$ on days 0 and 14, which is the regimen used for lymphoproliferative disease and rheumatoid arthritis. However, the optimal regimen, including dose and frequency, has not yet been fully established in LN. Low-dose rituximab therapy $(500 \mathrm{mg} \times 2$ ) successfully reduced CD19 B cells for up to 90 days in the nephrology practice [43]. Likewise, a single dose of rituximab $375 \mathrm{mg} / \mathrm{m}^{2}$ induced favorable outcomes with prolonged $\mathrm{B}$ cell depletion in the refractory LN [44]. A study of membranous nephropathy revealed that the regimen of rituximab $375 \mathrm{mg} / \mathrm{m}^{2}$ weekly for 4 weeks depleted more B cell than the regimen of rituximab 1,000 mg twice with a 2-week interval [45]. In addition to these issues, there is a lack of consensus on various strategies for using rituximab, such as maintenance therapy and immunogenicity. Further research is needed on the effective use of rituximab in the treatment of $\mathrm{LN}$. On the other hand, the autoantibody profile is useful to understand the lupus subtype and predict the outcome in SLE. In LN, the presence of anti-Sm is associated with poor renal outcome [46]. Anti-dsDNA contributes to the pathogenesis of $\mathrm{LN}$ by deposition of immune complexes in mesangial matrix and binding exposed chromatin fragments in glomerular basement membrane [47]. We found that the positive anti-La was also associated with good renal response of rituximab. This result is consistent with the previous opinion that anti-La has a protective effect from LN [48].

There were some limitations to this study. First, the sample size was small. Second, this was a retrospective study performed at a single center. Third, some baseline characteristics differed between the groups, possibly affecting the renal response. However, the multivariate Cox analysis was used to adjust the influence of other clinical values and identify the effect of GFR. Finally, we used estimated GFR in this study, which may not reflect the actual GFR in some cases. Within these limitations, this study showed an association between renal function at the start of rituximab therapy and renal response in refractory or relapsing $\mathrm{LN}$.

\section{CONCLUSION}

Patients with refractory or relapsing $\mathrm{LN}$ treated with rituximab achieved good renal response in 12 months. Those with preserved renal function at the start of rituximab therapy had better renal response than those with renal impairment. This result may provide useful information in determining rituximab therapy in patients with refractory or relapsing $\mathrm{LN}$ based on renal function.

\section{ACKNOWLEDGMENTS}

This work was supported by a grant from the National Research Foundation of Korea to YG Kim (NRF-2019R 1F1A1059736).

\section{CONFLIC OF INTEREST}

No potential conflict of interest relevant to this article was reported.

\section{AUTHOR CONTRIBUTIONS}

S.H., C.K.L., B.Y., and Y.G.K. were involved in conception and design of study. S.J.C., S.M.A., J.S.O., and Y.G.K. were contributed to acquisition, analysis and interpretation of data. All authors were involved in drafting and revising the manuscript critically for important intellectual content and final approval of the version to be published.

\section{REFERENCES}

1. Ginzler EM, Dooley MA, Aranow C, Kim MY, Buyon J, Merrill JT, et al. Mycophenolate mofetil or intravenous cyclophosphamide for lupus nephritis. N Engl J Med 2005; 
353:2219-28.

2. Houssiau FA, Vasconcelos C, D'Cruz D, Sebastiani GD, Garrido Ed Ede R, Danieli MG, et al. Immunosuppressive therapy in lupus nephritis: the Euro-Lupus Nephritis Trial, a randomized trial of low-dose versus high-dose intravenous cyclophosphamide. Arthritis Rheum 2002;46:2121-31.

3. Ramos L, Isenberg D. Rituximab: the lupus journey. Curr Treatm Opt Rheumatol 2015;1:30-41.

4. Smolen JS, Landewé RBM, Bijlsma JWJ, Burmester GR, Dougados M, Kerschbaumer A, et al. EULAR recommendations for the management of rheumatoid arthritis with synthetic and biological disease-modifying antirheumatic drugs: 2019 update. Ann Rheum Dis 2020;79: 685-99.

5. Stone JH, Merkel PA, Spiera R, Seo P, Langford CA, Hoffman GS, et al. Rituximab versus cyclophosphamide for ANCA-associated vasculitis. N Engl J Med 2010;363: 221-32.

6. Rovin BH, Furie R, Latinis K, Looney RJ, Fervenza FC, Sanchez-Guerrero J, et al. Efficacy and safety of rituximab in patients with active proliferative lupus nephritis: the Lupus Nephritis Assessment with Rituximab study. Arthritis Rheum 2012;64:1215-26.

7. Weidenbusch M, Römmele C, Schröttle A, Anders HJ. Beyond the LUNAR trial. Efficacy of rituximab in refractory lupus nephritis. Nephrol Dial Transplant 2013;28:106-11.

8. Moroni G, Raffiotta F, Trezzi B, Giglio E, Mezzina N, Del Papa N, et al. Rituximab vs mycophenolate and vs cyclophosphamide pulses for induction therapy of active lupus nephritis: a clinical observational study. Rheumatology (Oxford) 2014;53:1570-7.

9. Shin JS, Kim KN. Catastrophic antiphospholipid syndrome associated with systemic lupus erythematosus successfully treated with rituximab: a case report. J Rheum Dis 2019; 26:74-8.

10. Austin HA 3rd, Boumpas DT, Vaughan EM, Balow JE. Predicting renal outcomes in severe lupus nephritis: contributions of clinical and histologic data. Kidney Int 1994; 45:544-50.

11. Liu G, Wang H, Le J, Lan L, Xu Y, Yang Y, et al. Early-stage predictors for treatment responses in patients with active lupus nephritis. Lupus 2019;28:283-9.

12. Weening JJ, D'Agati VD, Schwartz MM, Seshan SV, Alpers CE, Appel GB, et al. The classification of glomerulonephritis in systemic lupus erythematosus revisited. J Am Soc Nephrol 2004;15:241-50.

13. Bertsias GK, Tektonidou M, Amoura Z, Aringer M, Bajema I, Berden JH, et al. Joint European League Against Rheumatism and European Renal Association-European Dialysis and Transplant Association (EULAR/ERA-EDTA) recommendations for the management of adult and paediatric lupus nephritis. Ann Rheum Dis 2012;71:1771-82.

14. Fernandes das Neves M, Irlapati RV, Isenberg D. Assessment of long-term remission in lupus nephritis patients: a retrospective analysis over 30 years. Rheumatology (Oxford) 2015;54:1403-7.

15. Chavarot N, Verhelst D, Pardon A, Caudwell V, Mercadal L, Sacchi A, et al. Rituximab alone as induction therapy for membranous lupus nephritis: a multicenter retrospective study. Medicine (Baltimore) 2017;96:e7429.

16. Pepper R, Griffith M, Kirwan C, Levy J, Taube D, Pusey C, et al. Rituximab is an effective treatment for lupus nephritis and allows a reduction in maintenance steroids. Nephrol Dial Transplant 2009;24:3717-23.

17. Condon MB, Ashby D, Pepper RJ, Cook HT, Levy JB, Griffith $\mathrm{M}$, et al. Prospective observational single-centre cohort study to evaluate the effectiveness of treating lupus nephritis with rituximab and mycophenolate mofetil but no oral steroids. Ann Rheum Dis 2013;72:1280-6.

18. Jónsdóttir T, Zickert A, Sundelin B, Henriksson EW, van Vollenhoven RF, Gunnarsson I. Long-term follow-up in lupus nephritis patients treated with rituximab--clinical and histopathological response. Rheumatology (Oxford) 2013; 52:847-55.

19. Tsanyan ME, Soloviev SK, Radenska-Lopovok SG, Torgashina AV, Nikolaeva EV, Khrennikov YB, et al. Clinical and morphological improvement of lupus nephritis treated with rituximab. Folia Med (Plovdiv) 2014;56: 245-52.

20. Gunnarsson I, Sundelin B, Jónsdóttir T, Jacobson SH, Henriksson EW, van Vollenhoven RF. Histopathologic and clinical outcome of rituximab treatment in patients with cyclophosphamide-resistant proliferative lupus nephritis. Arthritis Rheum 2007;56:1263-72.

21. Melander C, Sallée M, Trolliet P, Candon S, Belenfant X, Daugas E, et al. Rituximab in severe lupus nephritis: early B-cell depletion affects long-term renal outcome. Clin J Am Soc Nephrol 2009;4:579-87.

22. Gomez Mendez LM, Cascino MD, Garg J, Katsumoto TR, Brakeman P, Dall'Era M, et al. Peripheral blood B cell depletion after rituximab and complete response in lupus nephritis. Clin J Am Soc Nephrol 2018;13:1502-9.

23. Vigna-Perez M, Hernández-Castro $B$, Paredes-Saharopulos O, Portales-Pérez D, Baranda L, Abud-Mendoza C, et al. Clinical and immunological effects of Rituximab in patients with lupus nephritis refractory to conventional therapy: a pilot study. Arthritis Res Ther 2006;8:R83.

24. Goswami RP, Sircar G, Sit H, Ghosh A, Ghosh P. Cyclophosphamide versus mycophenolate versus rituximab in lupus nephritis remission induction: a historical headto-head comparative study. J Clin Rheumatol 2019;25: 28-35.

25. Iaccarino L, Bartoloni E, Carli L, Ceccarelli F, Conti F, De Vita S, et al. Efficacy and safety of off-label use of rituximab in refractory lupus: data from the Italian Multicentre Registry. Clin Exp Rheumatol 2015;33:449-56.

26. Contis A, Vanquaethem H, Truchetet ME, Couzi L, Rigothier C, Richez C, et al. Analysis of the effectiveness and safety of rituximab in patients with refractory lupus nephritis: a chart review. Clin Rheumatol 2016;35:517-22.

27. Fanouriakis A, Kostopoulou M, Cheema K, Anders HJ, Aringer M, Bajema I, et al. 2019 Update of the Joint European League Against Rheumatism and European Renal Association-European Dialysis and Transplant Association (EULAR/ERA-EDTA) recommendations for the management of lupus nephritis. Ann Rheum Dis 2020;79:713-23.

28. Yap DY, Chan TM. Lupus nephritis in Asia: clinical features and management. Kidney Dis (Basel) 2015;1:100-9.

29. Bang SY, Lee CK, Kang YM, Kim HA, Suh CH, Chung WT, et al. Multicenter retrospective analysis of the effectiveness and safety of rituximab in Korean patients with refractory systemic lupus erythematosus. Autoimmune Dis 2012; 
2012:565039.

30. Tanaka Y, Takeuchi T, Miyasaka N, Sumida T, Mimori T, Koike T, et al. Efficacy and safety of rituximab in Japanese patients with systemic lupus erythematosus and lupus nephritis who are refractory to conventional therapy. Mod Rheumatol 2016;26:80-6.

31. Díaz-Lagares C, Croca S, Sangle S, Vital EM, Catapano F, Martínez-Berriotxoa A, et al. Efficacy of rituximab in 164 patients with biopsy-proven lupus nephritis: pooled data from European cohorts. Autoimmun Rev 2012;11:357-64.

32. Corapi KM, Dooley MA, Pendergraft WF 3rd. Comparison and evaluation of lupus nephritis response criteria in lupus activity indices and clinical trials. Arthritis Res Ther 2015; 17:110.

33. Patel SB, Korbet SM, Lewis EJ. The prognosis of severe lupus nephritis based on the Modification of Diet in Renal Disease (MDRD) study estimated glomerular filtration rate. Lupus 2011;20:256-64.

34. Dall'Era M, Stone D, Levesque V, Cisternas M, Wofsy D. Identification of biomarkers that predict response to treatment of lupus nephritis with mycophenolate mofetil or pulse cyclophosphamide. Arthritis Care Res (Hoboken) 2011;63:351-7.

35. Haridasan S, Rathi M, Sharma A, Nada R, Kumar S, Ramachandran R, et al. Outcome of biopsy-proven lupus nephritis with low glomerular filtration rate at presentation. Int J Rheum Dis 2020;23:1201-9.

36. Rivera F, Fulladosa X, Poveda R, Frutos MA, García-Frías P, Ara J, et al. Mycophenolate as induction therapy in lupus nephritis with renal function impairment. Am J Nephrol 2012;35:424-33.

37. Rivera F, Illescas ML, López-Rubio E, Fulladosa J, Poveda R, Baltar J, et al. Mycophenolate as maintenance therapy for lupus nephritis with impaired renal function. Am J Nephrol 2013;37:509-17.

38. Lindholm C, Börjesson-Asp K, Zendjanchi K, Sundqvist AC, Tarkowski A, Bokarewa M. Longterm clinical and immunological effects of anti-CD20 treatment in patients with re- fractory systemic lupus erythematosus. J Rheumatol 2008; 35:826-33.

39. Zhang J, Zhao Z, Hu X. Effect of rituximab on serum levels of anti-Clq and antineutrophil cytoplasmic autoantibodies in refractory severe lupus nephritis. Cell Biochem Biophys 2015;72:197-201.

40. Kraaij T, Kamerling SWA, de Rooij ENM, van Daele PLA, Bredewold OW, Bakker JA, et al. The NET-effect of combining rituximab with belimumab in severe systemic lupus erythematosus. J Autoimmun 2018;91:45-54.

41. Li EK, Tam LS, Zhu TY, Li M, Kwok CL, Li TK, et al. Is combination rituximab with cyclophosphamide better than rituximab alone in the treatment of lupus nephritis? Rheumatology (Oxford) 2009;48:892-8.

42. Lateef A, Lahiri M, Teng GG, Vasoo S. Use of rituximab in the treatment of refractory systemic lupus erythematosus: Singapore experience. Lupus 2010;19:765-70.

43. George J, Alex S, Thomas ETA, Gracious N, Vineetha NS, Kumar S. Clinical response and pattern of B cell suppression with single low dose rituximab in nephrology. Kidney360 2020;1:359-67.

44. Kotagiri P, Martin A, Hughes P, Becker G, Nicholls K. Single-dose rituximab in refractory lupus nephritis. Intern Med J 2016;46:899-901.

45. Fervenza FC, Abraham RS, Erickson SB, Irazabal MV, Eirin A, Specks U, et al. Rituximab therapy in idiopathic membranous nephropathy: a 2-year study. Clin J Am Soc Nephrol 2010;5:2188-98

46. Ahn SS, Yoo BW, Song JJ, Park YB, Lee SK, Lee SW. Anti-Sm is associated with the early poor outcome of lupus nephritis. Int J Rheum Dis 2016;19:897-902.

47. Rekvig OP, Putterman C, Casu C, Gao HX, Ghirardello A Mortensen ES, et al. Autoantibodies in lupus: culprits or passive bystanders? Autoimmun Rev 2012;11:596-603.

48. Cozzani E, Drosera M, Gasparini G, Parodi A. Serology of lupus erythematosus: correlation between immunopathological features and clinical aspects. Autoimmune Dis 2014;2014:321359. 